arthritis. a meta-analysis of literature studies. Thromb Haemost 2015;113:916930

[2] Crilly M. et al. Arterial stiffness and cumulative inflammatory burden in rheumatoid arthritis:a dose-response relationship independent of established cardiovascular risk factors Rheumatology 2009;48:1606-1612.

[3] Silem H., Nasr G. Change of the aortic elasticity in rheumatoid arthritis: Relationship to associated cardiovascular risk factors $\mathrm{J}$ Cardiovasc Dis Res. 2010;1:110-115.

Disclosure of Interest: None declared

DOI: 10.1136/annrheumdis-2017-eular.6495

\section{AB0315 THE POTENTIAL ASSOCIATION BETWEEN RHEUMATOID ARTHRITIS AND TRADITIONAL CARDIOVASCULAR RISK FACTORS: A META-ANALYSIS OF CONTROLLED STUDIES}

E. Filhol $^{1}$, C. Gaujoux-Viala ${ }^{2}$, B. Combe ${ }^{1}$, J. Morel $^{1}$, C. Hua ${ }^{1}$, A. Nutz ${ }^{2}$, C. Lukas ${ }^{1}$, F. Flaisler ${ }^{2} .{ }^{1}$ Lapeyronie Hospital, Montpellier; ${ }^{2}$ Nimes Hospital, Nimes, France

Background: Systemic inflammation is the cornerstone of both rheumatoid arthritis (RA) and atherosclerosis. RA is currently considered as a cardiovascular risk factor.

Objectives: The aim of this systematic review was to assess the association between RA and the traditional cardiovascular risk factors (hypertension, dyslipidemia, diabete mellitus, and atherosclerosis) in RA patients in comparison to the general population.

Methods: We systematically searched literature (via Pubmed, Cochrane and abstracts from recent ACR and EULAR congresses) up to March 2016 for observational studies providing data concerning the presence of a traditional cardiovascular risk factor (among hypertension, dyslipidemia, diabetes mellitus, atherosclerosis) in patients with RA and in a control group. A meta-analysis of the relative risk $(R R)$ concerning patients with $R A$ in relation to the control group was performed for each cardiovascular risk factor.

Results: Out of 5714 screened references, 13 studies were included. Due to lack of data, atherosclerosis studies could not be included in this meta-analysis. For hypertension and diabetes, an increased risk was observed: $R R=1.15$ [95\% Cl 1.07-1.24], $p=0.0003$ and $R R=1.11$ [1.04-1.19], $p=0.001$, respectively. On the contrary, not any association was found with the dyslipidemia ( $R R=0.93$ [0.77-1.12], $p=0.43$ ).

Conclusions: This meta-analysis highlights a moderate excess risk of hypertension and diabetes among patients with RA relative to the general population. A comprehensive identification of cardiovascular risk profile of RA is an opportunity to improve health management of these patients. Future research is crucial in order to establish to what extent the control of modifiable risk factors can improve cardiovascular outcome of these patients.

Disclosure of Interest: None declared

DOI: 10.1136/annrheumdis-2017-eular.5432

\section{AB0316 HOSPITAL ADMISSIONS OF PATIENTS WITH RHEUMATOID ARTHRITIS TREATED WITH DMARD}

E.C. Cervantes Pérez, J.R. Maneiro, A. Souto Vilas, J.A. Mera Varela, J.J. Gómez-Reino. Ramón Domínguez Foundation, University Hospital Complex of Santiago de Compostela, Santiago de Compostela, Spain

Objectives: To describe hospital admissions and contributing factors in patients with rheumatoid arthritis (RA) treated biological DMARD (b-DMAR) and conventional synthetic DMARD (cs-DMAR).

Methods: Retrospective observational study of RA patients admitted to the hospital for any cause from 2010 to 2015. Demographic, clinical and therapeutic characteristics were collected from the medical charts. Multivariate and univariate models were used to identify variables associated with admissions for any cause, major adverse cardiovascular events (MACE), and infection. The statistical program Stata 14.0 was used for the analysis.

Results: In the period $2010-2015,26 \%$ of all RA patients were treated with b-DMARD. There were a total of 1251 hospital admissions for any cause in 600 patients; 1055 admissions in 477 patients treated with cs-DMAR and 196 admissions in 123 patients treated with b-DMAR. Of the 1251 admissions, 251 were due to infections and 60 to MACE. Demographic characteristics,

Table, Demographic characteristics, comorbidities and treatment in 600 patients admitted to an university hospital.

\begin{tabular}{|l|c|c|c|c|}
\hline & $\begin{array}{l}\text { AR patients } \\
\text { admitted (600) }\end{array}$ & $\begin{array}{c}\text { Patients b-DMAR } \\
\text { treated (123) }\end{array}$ & $\begin{array}{c}\text { Patients cs-DMAR } \\
\text { treated (477) }\end{array}$ & $\mathrm{p}^{*}$ \\
\hline $\begin{array}{l}\text { Age }>65 \\
\text { years }\end{array}$ & 428 & $59(47.97 \%)$ & $369(77.36 \%)$ & 0.03 \\
\hline Female & 412 & $88(71.54 \%)$ & $324(67.93 \%)$ & 0.269 \\
\hline COPD & 59 & $8(6.96 \%)$ & $51(10.81 \%)$ & 0.062 \\
\hline $\begin{array}{l}\text { Diabetes } \\
\text { mellitus }\end{array}$ & 109 & $10(8.70 \%)$ & $99(20.97 \%)$ & 0.364 \\
\hline Dyslipemia & 161 & $23(20.00 \%)$ & $138(29.30 \%)$ & 0.025 \\
\hline $\begin{array}{l}\text { Arterial } \\
\text { hypertension }\end{array}$ & 295 & $41(35.65 \%)$ & $254(53.93 \%)$ & $<0.001$ \\
\hline $\begin{array}{l}\text { Corticoids } \\
\text { 'Chronic obstructive pulmonary disease, }\end{array}$ & $490.32 \%)$ & $403(85.74 \%)$ & 0.162 \\
\hline
\end{tabular}

comorbidities and treatment are disclosed in table. In the multivariate analysis, diabetes mellitus $(p<0.001)$, and hypertension $(p=0.029)$ were associated with admission for infections, and hypertension ( $p$ 0.011), and dyslipidemia $(p=0.02)$ with admissions for MACE.

Conclusions: infections and MACE are a significant cause of hospital admission in patients with rheumatoid arthritis. Comorbidities as diabetes, hypertension and dyslipidemia but not b-DMARD are significantly associated with admission for infection or MACE.

Disclosure of Interest: None declared

DOI: 10.1136/annrheumdis-2017-eular.6769

\section{AB0317 RHEUMATIC DISEASES AND PREGNANCY: PRACTICE PATTERNS AMONG RHEUMATOLOGISTS AND OBSTETRICIANS IN LEBANON}

F. Fayad ${ }^{1,2}$, N. Ziade ${ }^{1,2}$, G. Abi Karam ${ }^{1,2}$, W. Ghaname ${ }^{3,4} .{ }^{1}$ Saint Joseph University; ${ }^{2}$ Hotel Dieu de France University Hospital, Beirut; ${ }^{3}$ Holy Spirit University, Kaslik; ${ }^{4}$ Notre Dame de Secours University Hospital, Jbeil, Lebanon

Background: For years, women with potentially serious systemic diseases, such as rheumatic diseases (RD), have been advised against getting pregnant. However, with careful clinical management, most of these women can have successful pregnancies. The use of RD drugs before or during pregnancy is problematic due to the lack of knowledge about their compatibility with pregnancy. Recently, the British Society of Rheumatology (BSR) and the European League Against Rheumatism (EULAR) published guidelines on prescribing drugs in pregnancy and breastfeeding.

Objectives: To evaluate the perceptions and clinical practices of rheumatologists and obstetricians in Lebanon regarding the use of medications prior and during pregnancy and breastfeeding. The secondary objective was to assess the variables that are significantly associated with the physicians' adherence to guidelines.

Methods: A national, observational, cross-sectional physician survey was conducted among a representative sample of rheumatologists and obstetricians throughout Lebanon. Collected data included physicians' information (age, gen-

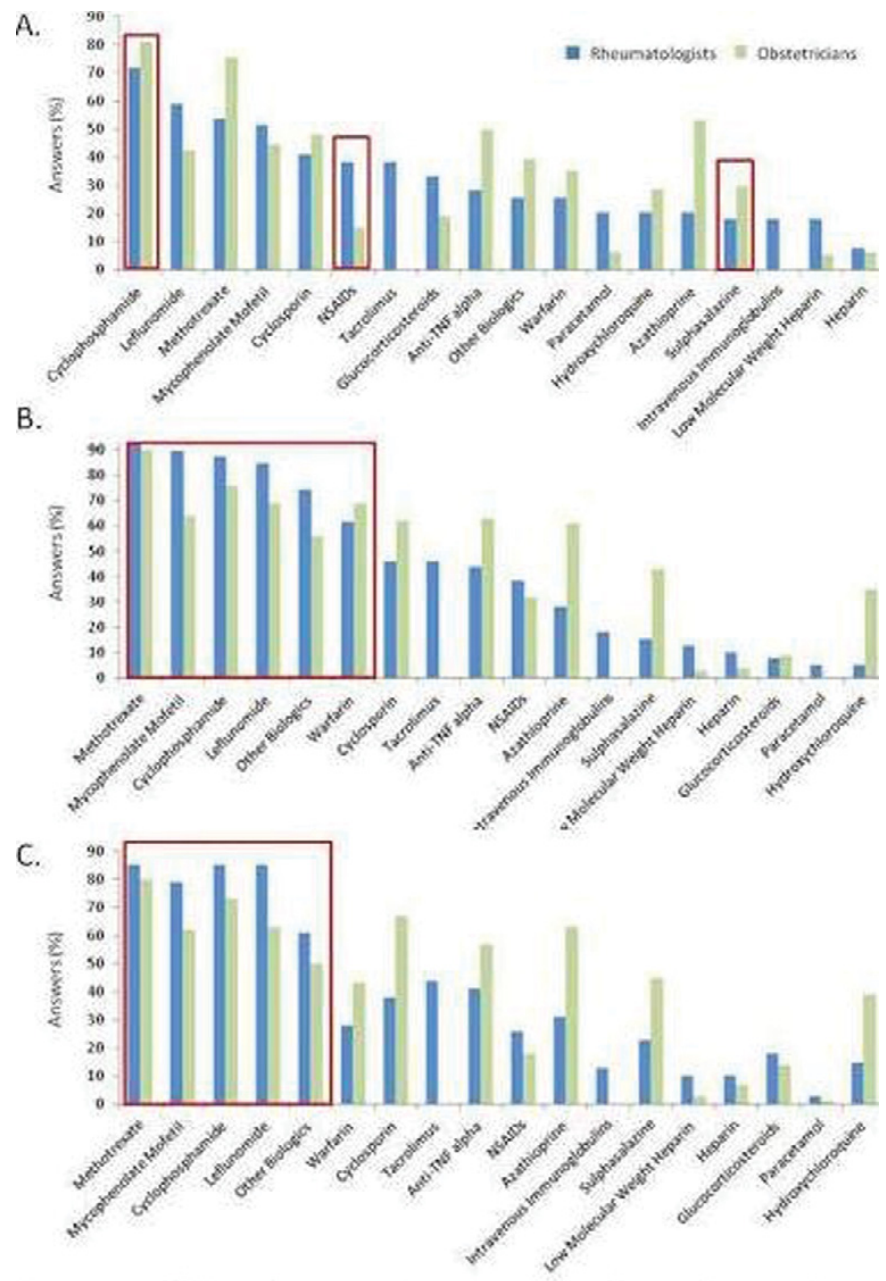

Figure 1. Percentage of rheumatologists and obstetricians who consider RD medications detrimental to fertility $(A)$, pregnancy $\{B\rangle$ and breastfeeding $\langle C\rangle$. Red squares indicate answers in accordance with EULAR/BSR guidelines. 